\title{
Wetting Behavior of Ternary Au-Ge-X (X = Sb, Sn) Alloys on $\mathrm{Cu}$ and $\mathrm{Ni}$
}

\author{
S. JIN,,$^{1,2}$ F. VALENZA ${ }^{3}$ R. NOVAKOVIC ${ }^{3}$ and C. LEINENBACH $^{1,4}$ \\ 1.-Empa - Swiss Federal Laboratories for Materials Science and Technology, Laboratory for \\ Joining Technologies and Corrosion, Überlandstrasse 129, 8600 Dübendorf, Switzerland. \\ 2.-Computational Materials Laboratory, Ecole Polytechnique Fédérale de Lausanne, Station 12, \\ 1015 Lausanne, Switzerland. 3.-National Research Council (CNR), Institute for Energetics and \\ Interphases (IENI), 16149 Genoa, Italy. 4.—e-mail: christian.leinenbach@empa.ch
}

\begin{abstract}
$\mathrm{Au}-\mathrm{Ge}-$ based alloys are potential substitutes for Pb-rich solders currently used for high-temperature applications. In the present work, the wetting behavior of two Au-Ge-X (X = Sb, Sn) ternary alloys, i.e., Au-15Ge-17Sb and Au-13.7 Ge-15.3Sn (at.\%), in contact with $\mathrm{Cu}$ and $\mathrm{Ni}$ substrates has been investigated. $\mathrm{Au}-13.7 \mathrm{Ge}-15.3 \mathrm{Sn}$ alloy showed complete wetting on both $\mathrm{Cu}$ and $\mathrm{Ni}$ substrates. Total spreading of $\mathrm{Au}-15 \mathrm{Ge}-17 \mathrm{Sb}$ alloy on $\mathrm{Cu}$ was also observed, while the final contact angle of this alloy on $\mathrm{Ni}$ was about $29^{\circ}$. Pronounced dissolution of $\mathrm{Cu}$ substrates into the solder alloys investigated was detected, while the formation of Ni-Ge intermetallic compounds at the interface of both solder/Ni systems suppressed the dissolution of Ni into the solder.
\end{abstract}

Key words: High-temperature solder, Au-Ge-based solder, wetting

\section{INTRODUCTION}

Au-Ge-based alloys have recently become of interest as potential lead-free solders for hightemperature applications. ${ }^{1-4}$ The Au-Ge phase diagram shows the existence of a simple eutectic at $634 \mathrm{~K}^{5}$ Besides, Au-Ge-based alloys also possess many interesting properties which are required for high-temperature solders: better thermal conductivity than currently used high-lead-content solders, ${ }^{6}$ good corrosion and oxidation resistance in the presence of high humidity at elevated temperatures, tendency for glass forming ${ }^{7}$ which eases production of thin foils that are much more convenient to be applied than paste in many applications, low natural radius of curvature for use in miniaturization industry, and excellent biocompatibility and workability for environmental and health considerations.

On the other hand, addition of elements with low melting points, such as $\mathrm{Sb}$, Sn or In, to the Au-Ge eutectic alloy leads to a further decrease of the melting point. ${ }^{1,8,9}$ In particular, addition of Sb to the $\mathrm{Au}-\mathrm{Ge}$ eutectic substantially improves its ductility. ${ }^{1}$

(Received November 22, 2012; accepted January 14, 2013;

published online March 5, 2013)
The wetting performance of solder alloys is very important, since it directly affects the integrity of solder interconnections. Study of wetting behavior is not only an important step in the characterization of solder alloys but also provides basic physicochemical data for design and development of novel lead-free solder alloys. However, rather limited information on the wetting behavior of Au-Ge-based alloys on relevant substrates is available. The wettability of Au-Ge alloy on $\mathrm{SiC}$ and Be substrates has been studied by Wang et al. and Gilliland, respectively. ${ }^{10,11}$ Strong wetting of Au-Ge eutectic alloy on $\mathrm{Cu}$ and $\mathrm{Ni}$ has been recently reported by Leinenbach et al. ${ }^{12}$ Wetting tests performed using Ag-AuGe solder alloys in contact with $\mathrm{Ni}$ substrate 13,14 revealed good wettability and interfacial bonding. However, no information is available on the wettability of other Au-Ge-based ternary solders so far.

The development of computational thermodynamics has accelerated the materials design process. In our previous work, ${ }^{8,9}$ the $\mathrm{Au}-\mathrm{Ge}-\mathrm{Sb}$ and $\mathrm{Au}-\mathrm{Ge}-\mathrm{Sn}$ ternary systems were thermodynamically assessed using the CALculation of PHAse Diagram (CALPHAD) method. ${ }^{15}$ Figures 1 and 2 show the calculated $\mathrm{Au}-\mathrm{Ge}-\mathrm{Sb}$ and $\mathrm{Au}-\mathrm{Ge}-\mathrm{Sn}$ liquidus projections from Refs. 8 and 9, respectively. Some alloy compositions 


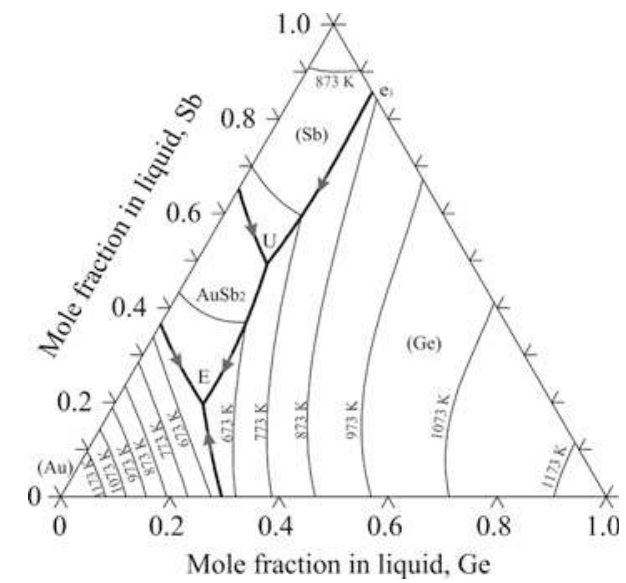

Fig. 1. Calculated liquidus projection of the Au-Ge-Sb ternary system. $^{7}$

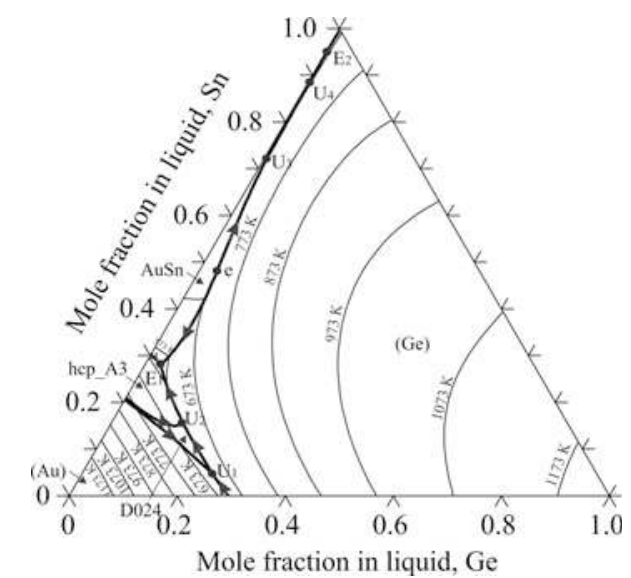

Fig. 2. Calculated liquidus projection of the Au-Ge-Sn ternary system. ${ }^{8}$

appear to be very promising in terms of their low melting temperatures, e.g., compositions around the ternary eutectic point [reaction: $\mathrm{L} \leftrightarrow(\mathrm{Au})+$ $\left.(\mathrm{Ge})+\mathrm{AuSb}_{2}\right]$ in the $\mathrm{Au}-\mathrm{Ge}-\mathrm{Sb}$ system with a calculated melting temperature of $560 \mathrm{~K}$ and the compositions around the ternary quasiperitectic point [reaction: L + D024 $\leftrightarrow(\mathrm{Ge})+$ hcp_A3] in the Au-GeSn system with a calculated melting temperature of $608 \mathrm{~K}$. Table I lists the calculated temperatures of the two above-mentioned invariant reactions and their compositions together with reported data from literature. $^{16,17}$ Since there is only a slight difference, we selected two ternary Au-Ge-based alloys, i.e., Au-15Ge$17 \mathrm{Sb}$ and $\mathrm{Au}-13.7 \mathrm{Ge}-15.3 \mathrm{Sn}$ (at.\%), whose compositions correspond to the invariant points reported in the literature, as our alloys of interest.

In the present work, the wetting behavior of $\mathrm{Au}-15 \mathrm{Ge}-17 \mathrm{Sb}$ and $\mathrm{Au}-13.7 \mathrm{Ge}-15.3 \mathrm{Sn}$ (at.\%) alloys in contact with $\mathrm{Cu}$ and $\mathrm{Ni}$ substrates has been investigated, followed by microstructural characterization of the interfaces.
For the sake of simplicity, the notation "AuGeSb" and "AuGeSn" is used to indicate the Au-15Ge-17Sb and $\mathrm{Au}-13.7 \mathrm{Ge}-15.3 \mathrm{Sn}$ (at.\%) alloys, respectively.

\section{EXPERIMENTAL PROCEDURES}

\section{Materials and Specimen Preparation}

Alloy samples of $1 \mathrm{~g}$ were produced from pure components $\mathrm{Au}, \mathrm{Ge}, \mathrm{Sb}$ (99.999 wt.\%), and $\mathrm{Sn}$ (99.9995 wt.\%; materials supplied by Alfa Aesar, Karlsruhe, Germany) by arc-melting under a purified argon atmosphere (99.999\%) using a nonconsumable tungsten electrode. All samples were melted six times and inverted three times to ensure homogeneity. In order to have a clean atmosphere during melting, a piece of pure Ti was firstly melted, acting as an oxygen getter. In addition, an oxygen removal cartridge in the argon line was used. Since the weight loss during melting was less than 0.4 mass $\%$, quantitative chemical analysis of the alloys was not conducted. Afterwards, the samples were cut into four pieces: one was used for the wetting test, another one for differential scanning calorimetry (DSC) measurements, and two as standbys.

Platelets with size of $10 \mathrm{~mm} \times 10 \mathrm{~mm} \times 0.6 \mathrm{~mm}$ were produced by laser cutting from pure $\mathrm{Cu}$ and $\mathrm{Ni}$ sheets (99.99 wt.\%; Alfa Aesar, Karlsruhe, Germany). The surface roughness of all platelets was $R_{\mathrm{a}}=$ $0.03 \mu \mathrm{m}$, measured on a length scale of $4.8 \mathrm{~mm}$. Prior to all tests, the platelets were degassed in a Torvac high-vacuum furnace (Cambridge Vacuum Engineering Ltd., Cambridge, UK) at $1073 \mathrm{~K}$ and under pressure of $2 \times 10^{-4} \mathrm{~Pa}$ for $1 \mathrm{~h}$. Afterwards, they were ultrasonically rinsed in ethanol and acetone and dried in air.

\section{DSC}

Solidus and liquidus temperatures were determined by differential scanning calorimetry (DSC) using a Netzsch DSC 404 F3 Pegasus with open alumina crucibles. The DSC cells were calibrated using the melting temperatures of the pure elements $\mathrm{Sn}, \mathrm{Bi}, \mathrm{Al}, \mathrm{In}, \mathrm{Ag}$, and $\mathrm{Au}$. The samples were polished and cleaned just before being measured in order to improve thermal contact and to avoid spurious or shifted transition peaks due to oxidation. Before each experiment, the DSC cell was evacuated three times and refilled with high-purity argon. Measurements were performed under continuous flow of argon at scanning rate of $10 \mathrm{~K} / \mathrm{min}$ for both heating and cooling. For each sample two heating/ cooling cycles were performed.

\section{Wetting Tests}

The wetting behavior was evaluated by contact angle $(\theta)$ and drop dimension (height and base diameter) measurements using the sessile drop technique. ${ }^{18}$ Experiments were carried out in a specially designed furnace, ${ }^{19}$ which is made of two concentric horizontal alumina tubes connected to a 
Table I. Possible ternary Au-Ge-X (X = Sb, Sn) solders

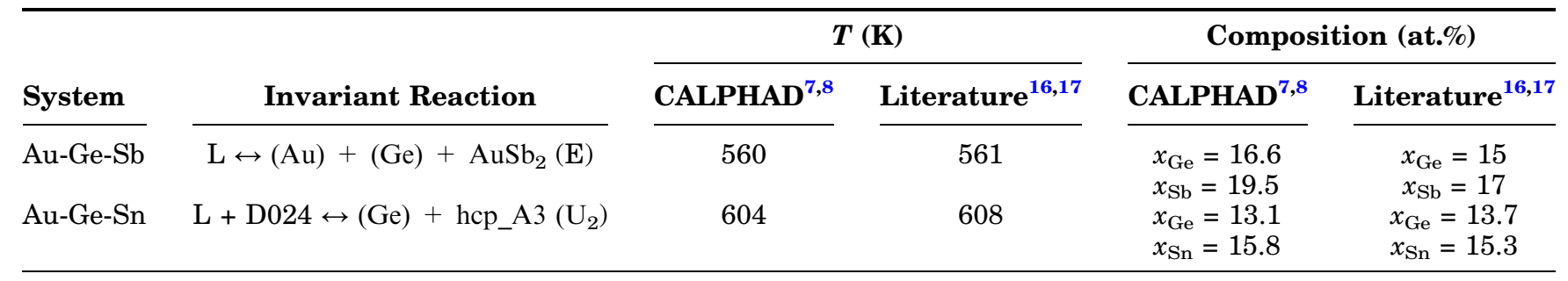

high-vacuum system. The pressure inside the inner tube can be kept at less than $10^{-4} \mathrm{~Pa}$ using a turbomolecular pump. Alternatively, controlled atmospheres can be introduced inside the working chamber. The oxygen partial pressure of the working atmosphere is continuously monitored by solid-state oxygen sensors at the chamber inlet and outlet. All measurements were performed at $T=643 \mathrm{~K}$ under a reducing atmosphere of $\mathrm{Ar} / 5$ vol. $\% \mathrm{H}_{2}$ mixture. To establish the effects of addition of a third component, the temperature was chosen the same as that of our previous wetting experiments with eutectic Au-Ge. ${ }^{12}$ To prevent oxidation phenomena with an "oxygenfree" atmosphere, a $\mathrm{Zr}$ foil placed over the liquid alloy sample was used as a getter to further reduce the oxygen content in the surrounding atmosphere. The wetting specimens were introduced into the preheated furnace by a magnetically operated push-rod only after all parameters (temperature and oxygen partial pressure) had reached equilibrium; complete melting occurred in about $30 \mathrm{~s}$. The solder alloy was rested on a perfectly leveled substrate, and the dropsubstrate couple was recorded in sharp, back-lit images using a high-resolution charge-coupled device (CCD) camera and processed with ASTRAView software ${ }^{20,21}$ in LabVIEW environment. The drop-substrate profile was acquired with precision of $\pm 1 \mu \mathrm{m}$ through careful determination of the magnification factor, while the contact angle data were evaluated with accuracy of $\pm 0.5^{\circ}$. All contact angle values reported represent averages of the left and right contact angles, which differed by less than $2 \%$. After the tests, the samples were moved into the colder part of the experimental apparatus, and cooled down to room temperature.

\section{Characterization Techniques}

After the wetting tests, cross-sections of the solder-substrate specimens were prepared using standard metallographic methods. The microstructures were investigated by scanning electron microscopy (SEM). All SEM images shown in this work were taken in backscattering (BS) mode. The compositions of the phases in the vicinity of the reaction interfaces were analyzed by energy-dispersive x-ray spectroscopy (EDX).

In addition, microhardness measurements were conducted on the cross-sections of the soldersubstrate specimens using Fischerscope HM2000 equipment at room temperature. On each sample, Vickers microindentations were made at areas of bulk substrate $(\mathrm{Ni}$ and $\mathrm{Cu}$ ) and solder-substrate interface. Special attention was paid to set properly the indenter for the defined specimen surface (bulk substrate, drop-substrate interface). An optimum load value of $5 \mathrm{mN}$ was chosen and applied to all the samples for $10 \mathrm{~s}$.

\section{RESULTS AND DISCUSSION}

\section{Solidus and Liquidus Temperatures}

DSC measurements were carried out on as-cast samples of AuGeSb and AuGeSn alloys. The temperatures of thermal effects in both heating cycles were in good agreement with each other. Phase transformation temperatures were taken from the heating curve. For comparison, solidus, liquidus, and invariant reaction temperatures of both alloys investigated were also calculated using the CALPHAD method. The thermodynamic parameters of the Au-Ge-Sb and Au-Ge-Sn ternary systems were taken directly from literature,, 8 and the calculation was performed using Thermo-Calc ${ }^{\circledR}$ software. $^{22}$ Table II summarizes some results of the present work: the solidus, ternary invariant reaction, and melting temperatures obtained from thermal analysis, CALPHAD calculation, and literature data. ${ }^{16,17}$

An invariant reaction at temperature of $588 \mathrm{~K}$ was found for the AuGeSb alloy (Table II), corresponding to the solidus temperature. However, this is $27 \mathrm{~K}$ higher than the value reported in Ref. 16 . The value reported by Zwingmann ${ }^{16}$ was determined using differential thermal analysis (DTA) with cooling rates of approximately $19 \mathrm{~K} / \mathrm{min}$ at $873 \mathrm{~K}$ and $8 \mathrm{~K} / \mathrm{min}$ at $573 \mathrm{~K}$, while the phase transformation temperatures obtained here were taken from the heating curve. The difference between our DSC result and the literature data can be attributed to the undercooling effect, since significant undercooling was observed during DSC measurements. On the other hand, the melting temperature of the AuGeSb alloy obtained in the present work is $607 \mathrm{~K}$. The corresponding phase transformation temperatures calculated using the CALPHAD method show that the AuGeSb alloy experienced first an invariant reaction at $560 \mathrm{~K}$, which agrees well with the literature data ${ }^{16}$ since the assessment of the Au-Ge-Sb system ${ }^{8}$ was based 
Table II. Summary of invariant reaction, solidus, and liquidus temperatures

\begin{tabular}{|c|c|c|c|}
\hline \multirow[b]{2}{*}{ Alloy (at.\%) } & \multicolumn{3}{|c|}{$T(\mathbf{K})$} \\
\hline & DSC (This Work) & CALPHAD $^{7,8}$ & Literature $^{16,17}$ \\
\hline $\begin{array}{l}\mathrm{Au}-15 \mathrm{Ge}-17 \mathrm{Sb} \\
\mathrm{Au}-13.7 \mathrm{Ge}-15.3 \mathrm{Sn}\end{array}$ & $\begin{array}{l}588^{\mathrm{a}, \mathrm{b}}, 607^{\mathrm{c}} \\
540^{\mathrm{a}, \mathrm{b}}, 633^{\mathrm{c}}\end{array}$ & $\begin{array}{c}560^{\mathrm{a}, \mathrm{b}}, 640^{\mathrm{c}} \\
540^{\mathrm{a}, \mathrm{b}}, 604^{\mathrm{b}}, 608^{\mathrm{c}}\end{array}$ & $\begin{array}{l}561^{\mathrm{a}, \mathrm{b}, \mathrm{c}} \\
608^{\mathrm{a}, \mathrm{b}, \mathrm{c}}\end{array}$ \\
\hline
\end{tabular}

${ }^{a}$ Solidus temperature. ${ }^{\mathrm{b}}$ Invariant reaction. ${ }^{\mathrm{c}}$ Liquidus temperature.

on this data. Later, the AuGeSb alloy completely melted at $640 \mathrm{~K}$, while only one phase transformation occurs according to the literature. ${ }^{16}$ This is most likely due to the deviation of the calculated liquid composition from the actual invariant reaction composition for the invariant reaction $\mathrm{L} \leftrightarrow$ $(\mathrm{Au})+(\mathrm{Ge})+\mathrm{AuSb}_{2}($ Table I)

In the case of the AuGeSn alloy, the present DSC measurements indicate the solidus (i.e., invariant reaction) and liquidus temperatures to be $T=540 \mathrm{~K}$ and $T=633 \mathrm{~K}$, respectively (Table II). It is interesting to notice that the ternary eutectic reaction $\mathrm{E} 1, \quad \mathrm{~L} \leftrightarrow(\mathrm{Ge})+\mathrm{hcp} \_\mathrm{A} 3+\mathrm{AuSn}, \quad$ reported by Redlich and Kister, ${ }^{17}$ has the same temperature $(540 \mathrm{~K})$ as we obtained by DSC for the AuGeSn alloy. CALPHAD calculations show that the (Ge) phase precipitates first from the AuGeSn liquid alloy. During cooling, the quasiperitectic reaction $\mathrm{L}+$ $\mathrm{D} 024 \leftrightarrow(\mathrm{Ge})+$ hcp_A3 occurs at $604 \mathrm{~K}$, and at the end the alloy solidifies completely through a ternary eutectic reaction $[\mathrm{L} \leftrightarrow(\mathrm{Ge})+$ hcp_A3 + AuSn $]$ at $540 \mathrm{~K}$. However, in the present DSC experiment, only one invariant reaction was observed, which should be the ternary eutectic reaction $\mathrm{L} \leftrightarrow(\mathrm{Ge})+$ hcp_A3 + AuSn, as suggested by Redlich and Kister. ${ }^{17}$ The quasiperitectic reaction $\mathrm{L}+\mathrm{D} 024 \leftrightarrow$ $(\mathrm{Ge})+$ hcp_A3 reported in Ref. 17 was not observed in the AuGeSn alloy investigated here. It should be noted that the quasiperitectic reaction composition ${ }^{17}$ was deduced from the measured vertical sections, where the uncertainty is large. The deviation of the alloy composition from the actual quasiperitectic reaction composition may lead to a different solidification path, which could explain the difference between the present DSC results and the literature data. ${ }^{17}$

\section{Wetting Behavior}

The wetting characteristics of the Au-Ge-X $(\mathrm{X}=\mathrm{Sb}, \mathrm{Sn}) / \mathrm{Cu}$ and $\mathrm{Au}-\mathrm{Ge}-\mathrm{X}(\mathrm{X}=\mathrm{Sb}, \mathrm{Sn}) / \mathrm{Ni}$ systems were determined under isothermal conditions at temperature of $T=643 \mathrm{~K}$ for $30 \mathrm{~min}$.

$$
\mathrm{Au}-\mathrm{Ge}-\mathrm{X}(\mathrm{X}=\mathrm{Sb}, \mathrm{Sn}) / \mathrm{Cu}
$$

The change of the contact angle, $\theta$, at $T=643 \mathrm{~K}$ as a function of time for the Au-Ge-X (X = Sb, Sn)/ $\mathrm{Cu}$ system is shown in Fig. 3. The wetting behavior of the AuGeSb and AuGeSn alloys in contact with

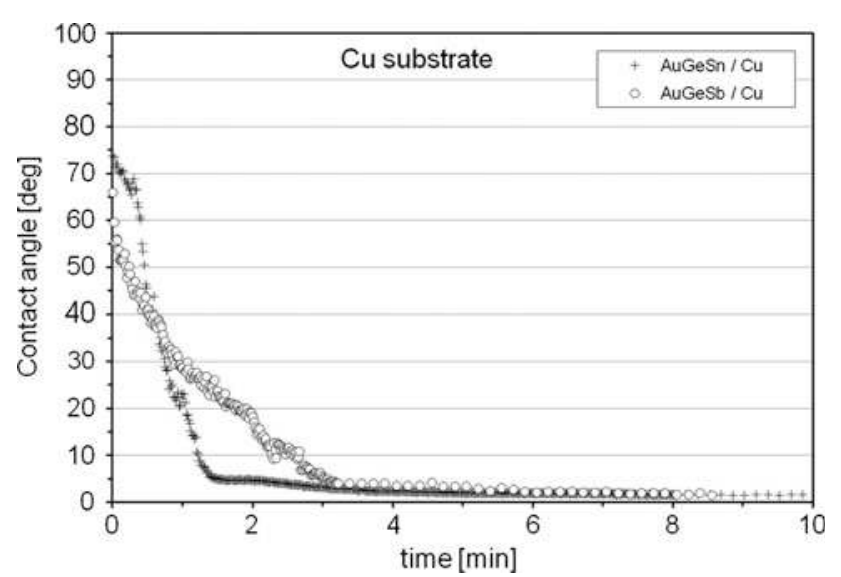

Fig. 3. Contact angle as a function of time for AuGeSb and AuGeSn on $\mathrm{Cu}$ substrate.

$\mathrm{Cu}$ substrate is similar. The systems are characterized by initial contact angle values of about $65^{\circ}$ and $75^{\circ}$, respectively. After melting, the contact angle of the $\mathrm{AuGeSb} / \mathrm{Cu}$ system decreased quickly and reached $\theta \approx 5^{\circ}$ within $3 \mathrm{~min}$, while in the case of AuGeSn/Cu, a sharp drop to $\theta \approx 5^{\circ}$ was observed after $1.5 \mathrm{~min}$. In both cases, the spreading was complete as the liquid phases wetted the underlying substrate perfectly.

The rate of change of the contact angle as a function of time was higher in the AuGeSn/Cu system in comparison with that observed for the $\mathrm{AuGeSb} / \mathrm{Cu}$ system (Fig. 3). Later, in both systems the liquid phase spread completely over the substrate, and thus the completely wetting liquid forms a zero contact angle $\left(\theta=0^{\circ}\right)$. It should be noted that, when the contact angle drops below $10^{\circ}$, image analysis software cannot provide reliable data since the height of the drop is too low and it is difficult to identify the triple line accurately. Compared with the wetting of Au-Ge eutectic binary alloy on $\mathrm{Cu},{ }^{12}$ addition of $\mathrm{Sb}$ and $\mathrm{Sn}$ further improved the wettability by solder alloys.

Metallographic examination of the $\mathrm{AuGeSb} / \mathrm{Cu}$ and $\mathrm{AuGeSn} / \mathrm{Cu}$ systems, for both the bulk alloy and the interface, were performed by SEM/EDX analysis. The top-view morphology of a solidified AuGeSb droplet on $\mathrm{Cu}$ substrate is shown in Fig. 4a. A white "strip" with composition of Au-38.6Cu-5Ge (at.\%) surrounds the droplet. Towards the center of the 

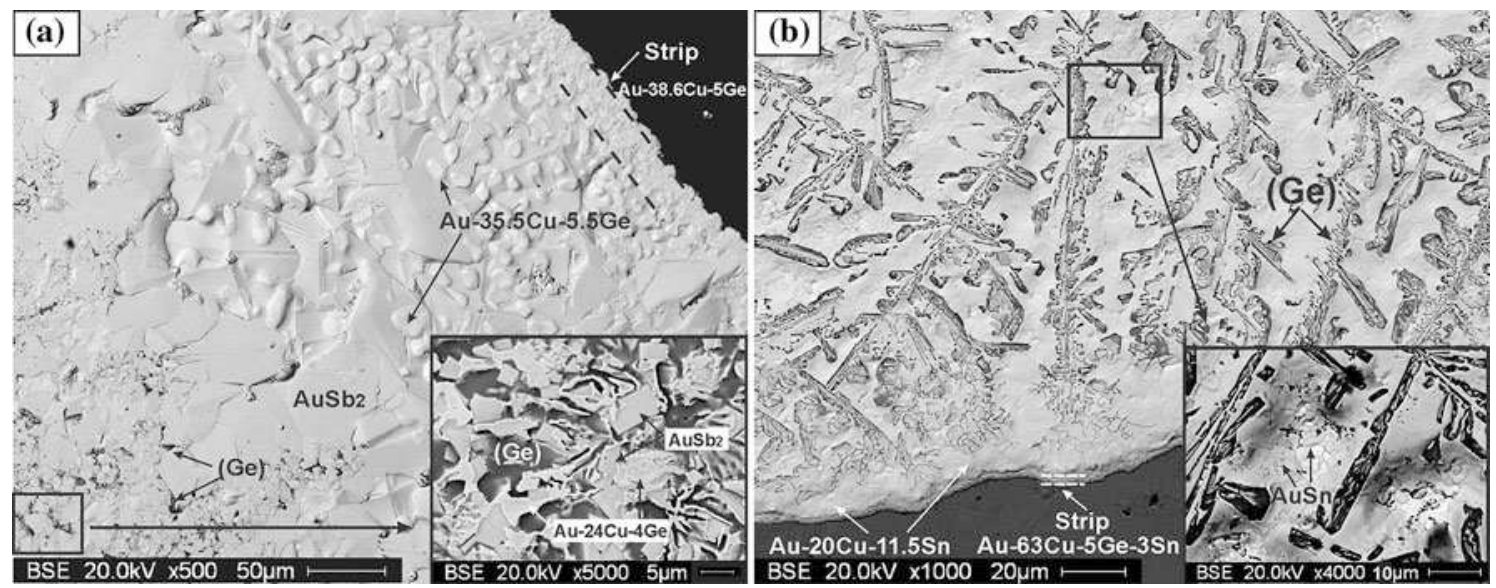

Fig. 4. Top-view morphology of the droplet after solidification: (a) AuGeSb on Cu, and (b) AuGeSn on Cu.

droplet, the presence of the $\mathrm{Au}-35.5 \mathrm{Cu}-5.5 \mathrm{Ge}$ (at.\%) phase ("round" patterns), dispersed on $\mathrm{AuSb}_{2}$-based matrix phase (Au-61.7Sb-2Cu, at.\%), was observed. A mixture of $\mathrm{AuSb}_{2}$-based phase (Au-61Sb-1.2Ge$0.6 \mathrm{Cu}$, at.\%), (Ge) phase, and $\mathrm{Au}-24 \mathrm{Cu}-4 \mathrm{Ge}$ (at.\%) phase was found at the center of the droplet. Similarly, in the AuGeSn/Cu system, a "strip" with composition Au-63Cu-5Ge-3Sn (at.\%) was identified around the AuGeSn droplet, as shown in Fig. 4b. A homogeneous morphology with large granular $(\mathrm{Ge})$ phase, Au-20Cu-11.5Sn (at.\%) matrix phase, and a small amount of AuSn (Au-46Sn, at.\%) phase was observed in the bulk alloy.

The interface microstructure of the AuGeSb solder on $\mathrm{Cu}$ substrate is shown in Fig. 5a. The formation of three thin reaction layers (each of about $1 \mu \mathrm{m}$ ) at the interface can be seen in the enlarged area in Fig. 5a. According to the EDX analysis, the compositions of layer 1, layer 2 , and layer 3 are $\mathrm{Au}-62 \mathrm{Cu}-8 \mathrm{Ge}-2 \mathrm{Sb}$ (at.\%), $\mathrm{Au}-72 \mathrm{Cu}-5 \mathrm{Ge}-6 \mathrm{Sb}$ (at.\%), and $\mathrm{Au}-82 \mathrm{Cu}-3 \mathrm{Sb}$ (at.\%), respectively, showing an increase of $\mathrm{Cu}$ content towards the $\mathrm{Cu}$ substrate. It should be pointed out that the identified compositions might have some uncertainties due to the small thickness of the interfacial layers. Since no further phase analysis, e.g., micro x-ray diffraction, was performed, the structure of the reaction layers remains unclear. According to the Au-Cu binary phase diagram, ${ }^{5}$ they could be the low-temperature ordered phases $\mathrm{AuCu}\left(\mathrm{L}_{1}\right)$ and $\mathrm{AuCu}_{3}\left(\mathrm{~L}_{2}\right)$ with some solubility of $\mathrm{Sb}$ and Ge elements.

In the solder alloy, three phases with different contrast were observed. The white matrix phase has composition of $\mathrm{Au}-31 \mathrm{Cu}-6 \mathrm{Ge}$ (at.\%), which corresponds to the low-temperature $\mathrm{Au}_{3} \mathrm{Cu}$ ordered phase according to the $\mathrm{Au}-\mathrm{Cu}$ phase diagram. ${ }^{5}$ However, literature ${ }^{23-25}$ shows that direct experiments below the order-disorder transition temperature $T_{\mathrm{c}} \approx 513 \mathrm{~K}$ are difficult because the diffusion rates are very low and even the best ordered samples contain significant disorder. Considering that the wetting test was performed at $T=643 \mathrm{~K}$, which is much higher than the order-disorder transition temperature, and that the processing time was relatively short, the structure of the white matrix (Fig. 5a) having composition $\mathrm{Au}-31 \mathrm{Cu}-6 \mathrm{Ge}$ (at.\%) is probably close to a face-centered cubic (fcc) $(\mathrm{Au}, \mathrm{Cu})$ solid solution with some solubility of Ge. The compositions of the other two phases, identified in the AuGeSb bulk alloy, are Au-61 at.\%Sb (grey area) and pure Ge (dark spots), respectively, corresponding to the $\mathrm{AuSb}_{2}$ and (Ge) phases (Fig. 5a).

A cross-section of the AuGeSn/Cu specimen is shown in Fig. 5b. A thin interfacial layer with thickness between $1.7 \mu \mathrm{m}$ and $2.5 \mu \mathrm{m}$ and composition of $\mathrm{Au}-70 \mathrm{Cu}-11 \mathrm{Ge}$ (at.\%) is formed between the AuGeSn solder and $\mathrm{Cu}$ substrate. According to the phase diagram, ${ }^{5}$ this interfacial product may correspond to an $\mathrm{AuCu}_{3}$-based low-temperature ordered phase with some solubility of Ge. In the solidified solder alloy, a white matrix with composition $\mathrm{Au}-20.6 \mathrm{Cu}-12 \mathrm{Sn}$ (at.\%), a phase with composition $\mathrm{Au}-45 \mathrm{Sn}-1 \mathrm{Cu}$ (at.\%; grey area), and pure $\mathrm{Ge}$ (dark spots) with dendrite morphology were identified. Similarly to the phases revealed in the AuGeSb/ $\mathrm{Cu}$ system, the white matrix phase observed in the $\mathrm{AuGeSn} / \mathrm{Cu}$ system probably has an fcc $(\mathrm{Au}, \mathrm{Cu})$ based structure with approximately 12 at.\% Sn. The other two phases identified on the interface are an AuSn-based phase with a small amount of $\mathrm{Cu}$ (due to dissolution of $\mathrm{Cu}$ substrate) and the (Ge) phase.

Pronounced dissolution of $\mathrm{Cu}$ into the liquid solder alloy was detected in both cases, as can be seen from Fig. 6. The solder drop extended beyond the previous edges of the $\mathrm{Cu}$ substrate. Moreover, by EDX analysis, about 31 at.\% $\mathrm{Cu}$ was found in the bulk alloy (white area) of the $\mathrm{AuGeSb} / \mathrm{Cu}$ specimen and about 21 at. $\% \mathrm{Cu}$ in the corresponding bulk phase of the AuGeSn/Cu specimen. The interfacial microstructure was affected by the solubility of $\mathrm{Cu}$ in the liquid alloy and by the dissolution of the $\mathrm{Cu}$ substrate. Indeed, the solid-liquid interface is not planar, and the formation of a crater (with depth of about $5 \mu \mathrm{m}$ ) under the drop was observed (Fig. 6). 

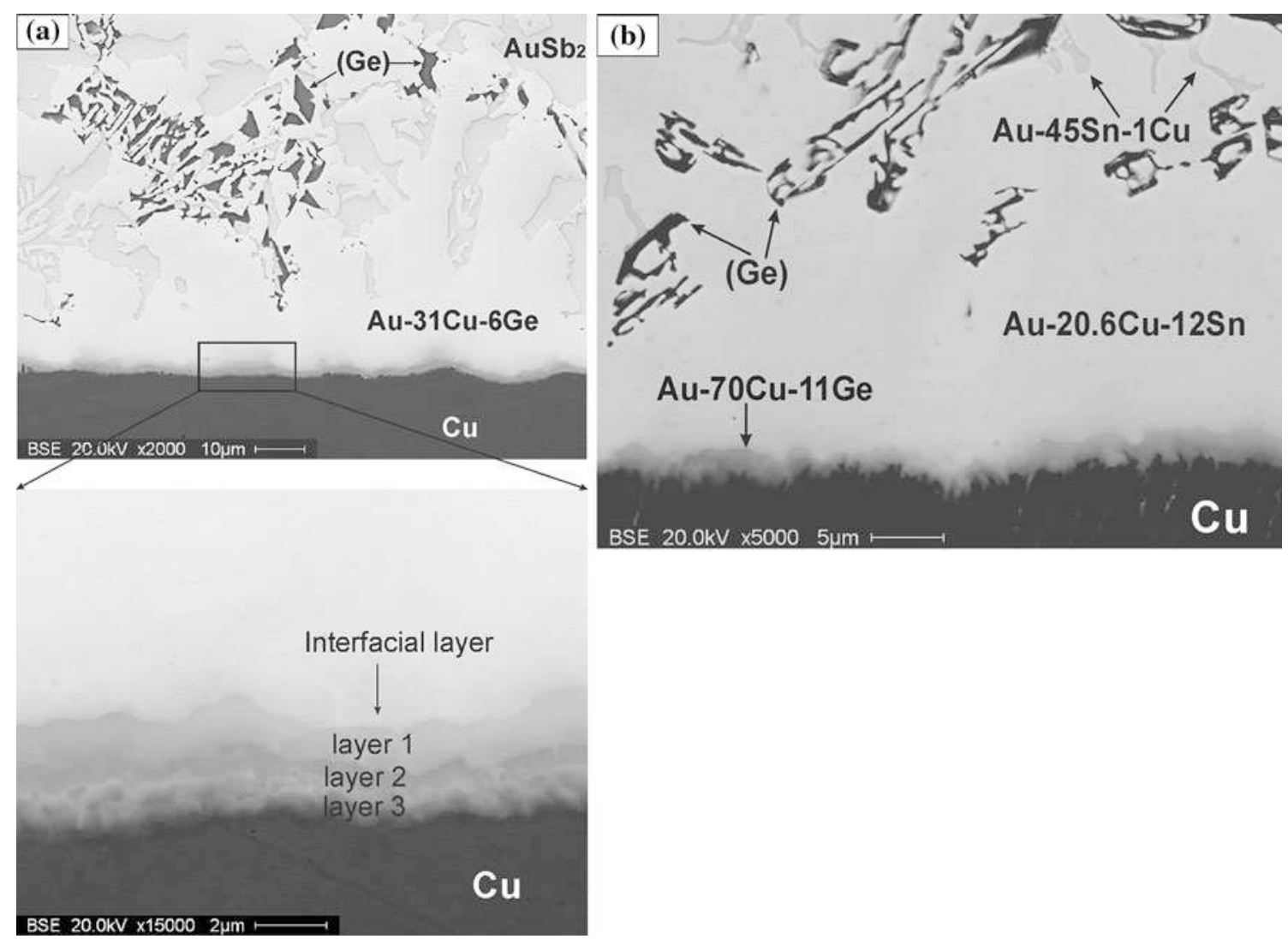

Fig. 5. Interfacial structure: (a) AuGeSb on Cu, and (b) AuGeSn on Cu.
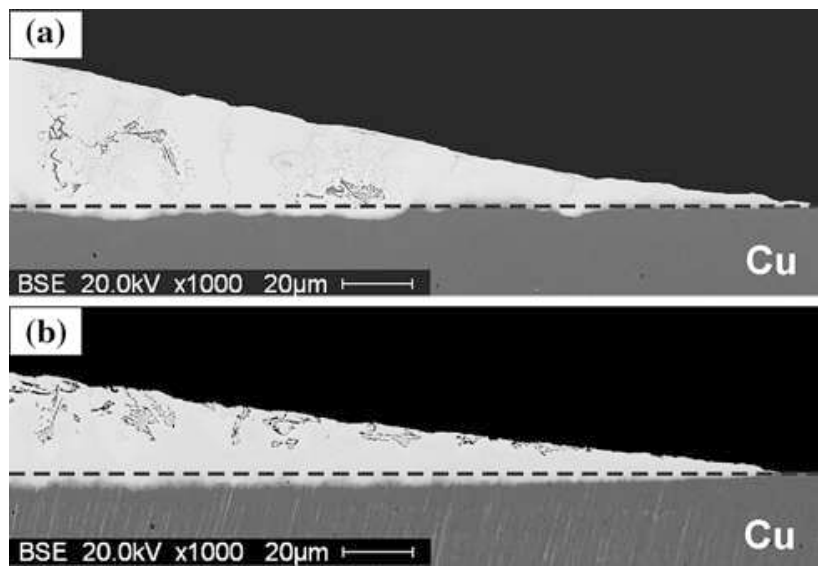

Fig. 6. Dissolution of $\mathrm{Cu}$ into the liquid solder alloy: (a) AuGeSb on $\mathrm{Cu}$, and (b) AuGeSn on Cu.

Accordingly, in both cases, $\theta \approx 5^{\circ}$ can be considered as an "apparent" contact angle. ${ }^{12}$

$$
\mathrm{Au}-\mathrm{Ge}-\mathrm{X}(\mathrm{X}=\mathrm{Sb}, \mathrm{Sn}) / \mathrm{Ni}
$$

The change of the contact angle at $T=643 \mathrm{~K}$ as a function of time for liquid Au-Ge-X (X = Sb, Sn) alloys in contact with $\mathrm{Ni}$ substrate is shown in Fig. 7. In the case of the $\mathrm{AuGeSb} / \mathrm{Ni}$ system, the

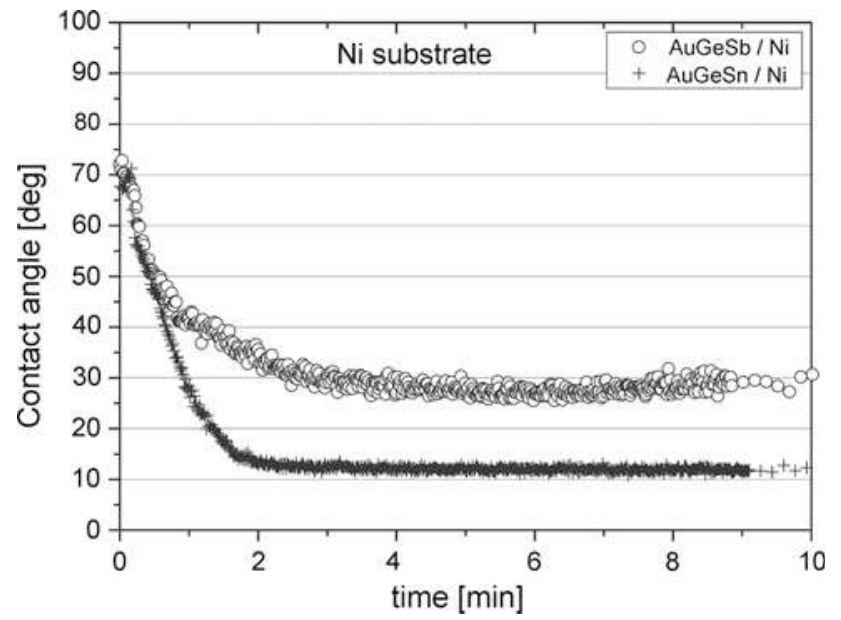

Fig. 7. Contact angle as a function of time for AuGeSb and AuGeSn on $\mathrm{Ni}$ substrate.

initial contact angle was about $73^{\circ}$. After $2 \mathrm{~min}$, it decreased to $35^{\circ}$ and then slowly reached the final contact angle value of about $29^{\circ}$. For the AuGeSn/Ni system, the initial contact angle of $72^{\circ}$ decreased and reached the final value of $\theta=11^{\circ}$ after about 3 min. In addition, during the experiment, the liquid AuGeSn alloy spread totally on the Ni substrate, reaching its edges. The spreading kinetics 
was slightly slower in the case of $\mathrm{AuGeSb} / \mathrm{Ni}$ in comparison with $\mathrm{AuGeSn} / \mathrm{Ni}$ (Fig. 7).

The formation of a layer of $\mathrm{AuSb}_{2}$-based phase (Au-58Sb-4Ge, at.\%) around the solidified droplet of the AuGeSb alloy was observed together with a discontinuous phase (white spots in Fig. 8a) with composition of $\mathrm{Au}-8 \mathrm{Ni}$ (at.\%) formed at the outer edge of the $\mathrm{AuSb}_{2}$ layer (Fig. 8a). This phase was presumably formed during the test rather than upon cooling, as it is solid at the testing temperature $(643 \mathrm{~K})$, and its presence at the triple line stopped the movement of the drop: this fact explains why for the $\mathrm{AuGeSb} / \mathrm{Ni}$ system the contact angle dropped slowly to $29^{\circ}$ and the system did not reach
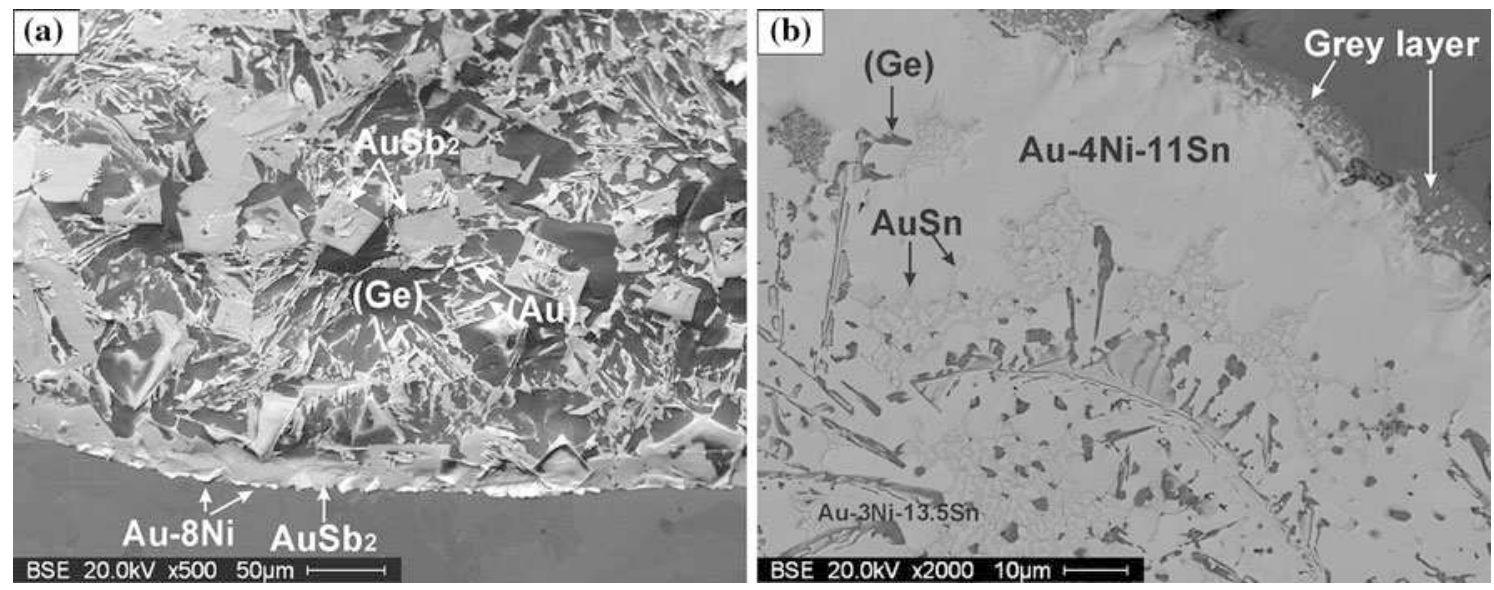

Fig. 8. Top-view morphology of the droplet after solidification: (a) AuGeSb on Ni, and (b) AuGeSn on Ni.
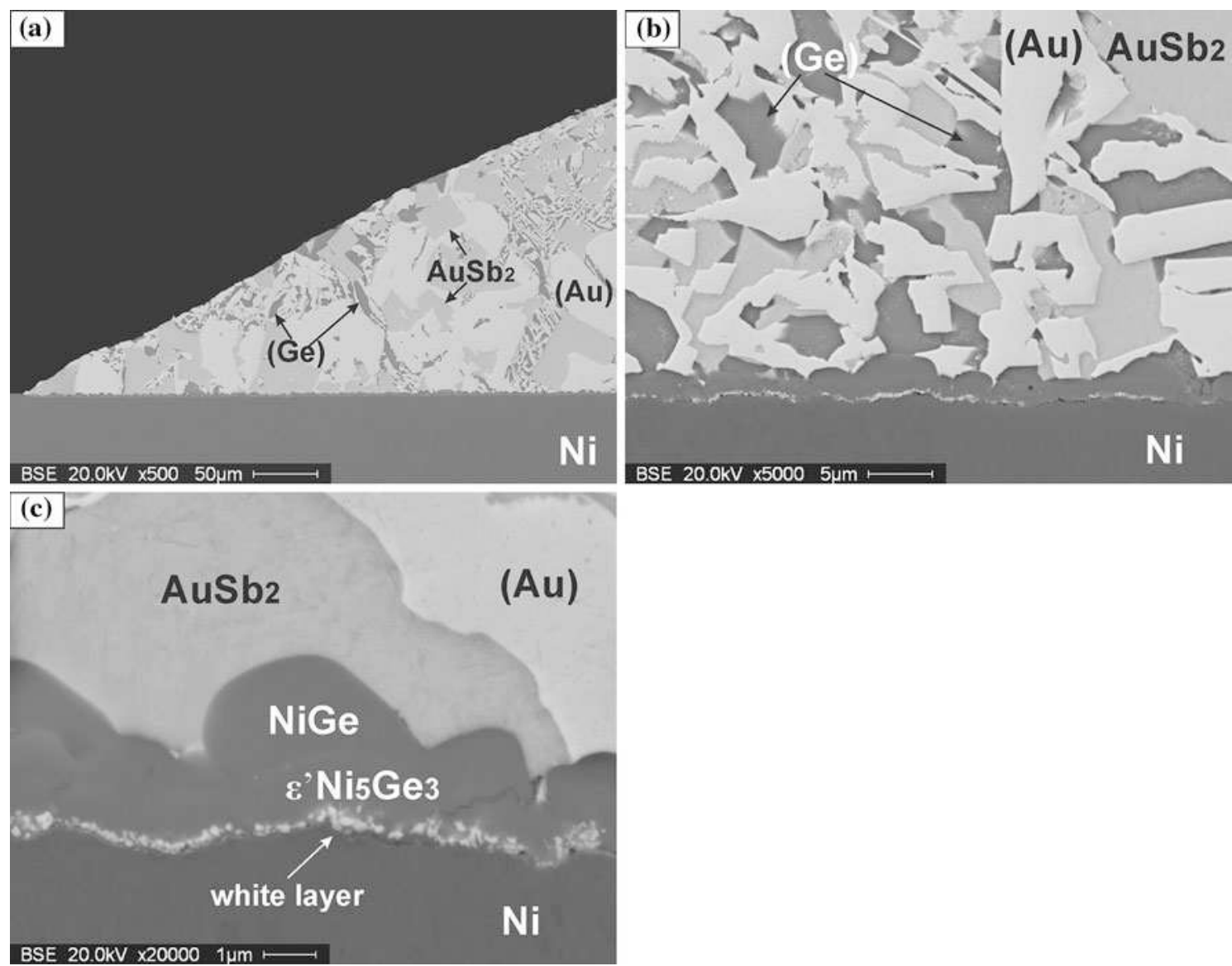

Fig. 9. Interfacial structure of $\mathrm{AuGeSb}$ on $\mathrm{Ni}$ : (a) close to the triple line, (b) enlarged interfacial structure, and (c) enlarged structure showing the white layer. 


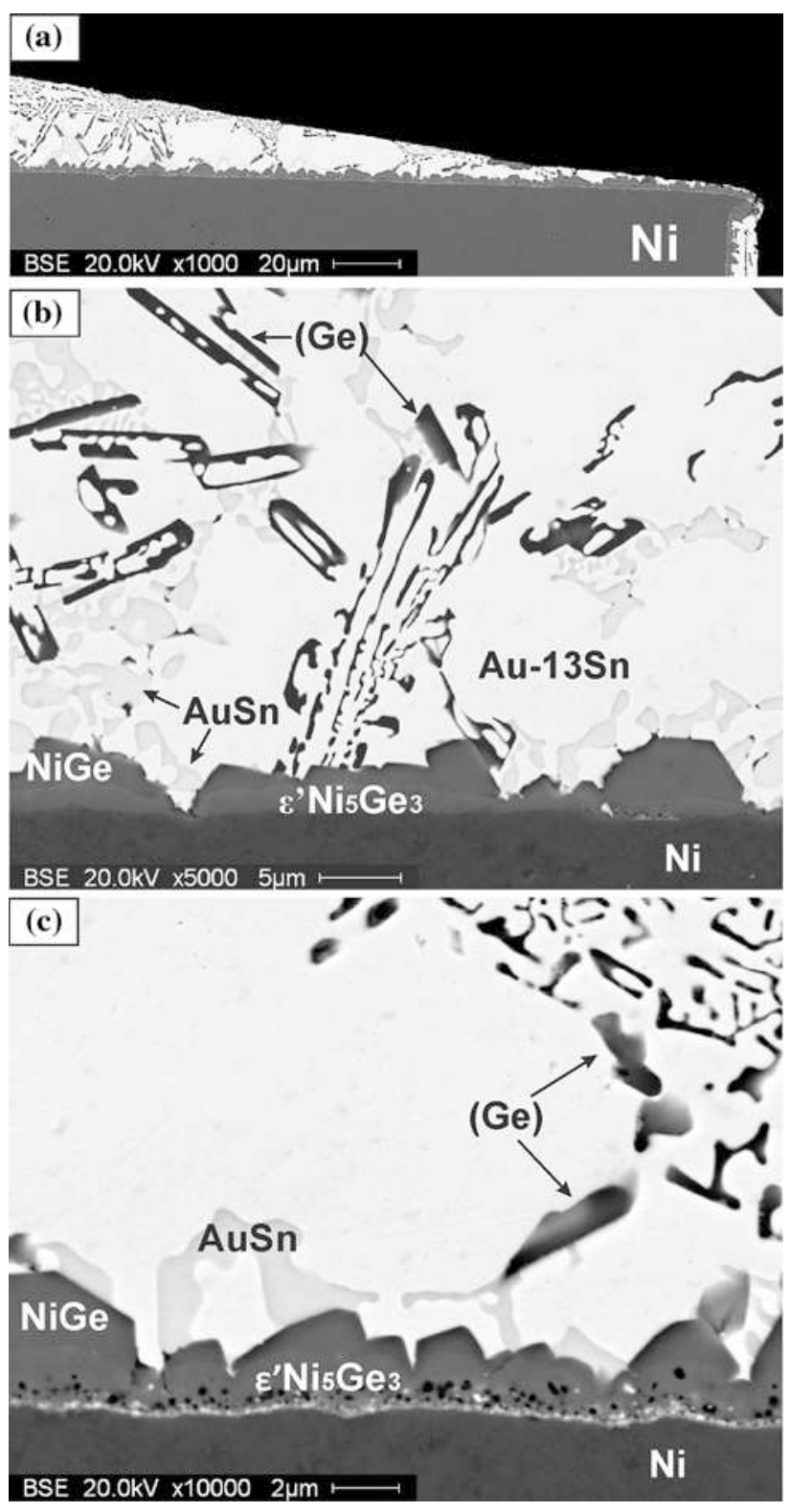

Fig. 10. Interfacial structure of AuGeSn on Ni: (a) close to the triple line, (b) enlarged interfacial structure at the center, and (c) enlarged interfacial structure close to the edge. total wetting during the tests. (Ge) matrix (dark area) with $\mathrm{AuSb}_{2}$-based phase (rectangular patterns) and $(\mathrm{Au})$ phase (needle-like patterns) were formed in the solidified droplet of solder alloy.

A top view of the AuGeSn/Ni system is shown in Fig. 8b. A grey layer with net morphology and an $\mathrm{Au}-$ rich zone with composition of $\mathrm{Au}-4 \mathrm{Ni}-11 \mathrm{Sn}$ (at.\%) surround the solidified droplet. Towards the center of the droplet, AuSn phase (round patterns) with composition of $\mathrm{Au}-45 \mathrm{Sn}$ (at.\%) forming a net structure and embedded in the Au-3Ni-13.5Sn matrix with large $(\mathrm{Ge})$ grains formed as well.

Figure 9a shows a cross-section of the AuGeSb/Ni system close to the triple line. The interfacial structure indicates the presence of interfacial layered compounds of $\mathrm{Ni}-37.5 \mathrm{Ge}-2.6 \mathrm{Au}($ at.\%) and $\mathrm{Ni}-49 \mathrm{Ge}-3 \mathrm{Au}$ (at.\%) with a characteristic irregular morphology of so-called scallops. The thickness of the first phase is found to be between $0.8 \mu \mathrm{m}$ and $1.3 \mu \mathrm{m}$, while in the case of the Ni-49Ge-3Au (at.\%) phase, its thickness varies from $0.8 \mu \mathrm{m}$ to $2 \mu \mathrm{m}$, as shown in Fig. 9b. The estimated average values are obtained by measuring the real thickness at different points along the cross-section.

The layer with composition Ni-49Ge-3Au (at.\%) is close to the NiGe compound, while the layer of $\mathrm{Ni}-37.5 \mathrm{Ge}-2.6 \mathrm{Au}$ (at.\%) is based on the low-temperature phase $\varepsilon^{\prime}-\mathrm{Ni}_{5} \mathrm{Ge}_{3}$. It should be noted that a very thin bright layer consisting of many small particles (white patterns in Fig. 9c) with thickness of less than $0.2 \mu \mathrm{m}$ was observed next to the $\mathrm{Ni}$ substrate. Its detection is beyond the resolution limits of our instruments. The explanation of the formation of those "white particles" requires further analysis, such as transmission electron microscopy (TEM). AuSb ${ }_{2}$ bulk phase, $(\mathrm{Ge})$, and $(\mathrm{Au})$ were identified in the solder alloy, and their compositions were $\mathrm{Au}-59 \mathrm{Sb}-1.5 \mathrm{Ge}$ (at.\%), pure $\mathrm{Ge}$, and pure $\mathrm{Au}$, respectively (Fig. 9).

The cross-sectional microstructure of the AuGeSn/ $\mathrm{Ni}$ specimen is shown in Fig. 10. Figure 10a confirms that the AuGeSn solder alloy spread completely and reached the edge of the Ni substrate. Two interfacial reaction products, NiGe-based (Ni-50 $\mathrm{Ge}-3 \mathrm{Au}$, at.\%) and $\varepsilon^{\prime}-\mathrm{Ni}_{5} \mathrm{Ge}_{3}$-based (Ni-38Ge-2.5Au,

Table III. Microhardness data after wetting experiments

\begin{tabular}{|c|c|c|c|}
\hline System & Test & Phase (at.\%) & Microhardness (HV) \\
\hline \multirow[t]{2}{*}{$\mathrm{AuGeSb} / \mathrm{Cu}$} & Substrate & $\mathrm{Cu}$ & 163 \\
\hline & Interface & $\mathrm{Au}-62 \mathrm{Cu}-8 \mathrm{Ge}-2 \mathrm{Sb}+\mathrm{Au}-72 \mathrm{Cu}-5 \mathrm{Ge}-6 \mathrm{Sb}+\mathrm{Au}-82 \mathrm{Cu}-3 \mathrm{Sb}$ & 340 \\
\hline \multirow{2}{*}{$\mathrm{AuGeSn} / \mathrm{Cu}$} & Substrate & $\mathrm{Cu}$ & 156 \\
\hline & Interface & $\mathrm{Au}-70 \mathrm{Cu}-11 \mathrm{Ge}$ & 400 \\
\hline \multirow[t]{2}{*}{$\mathrm{AuGeSb} / \mathrm{Ni}$} & Substrate & $\mathrm{Ni}$ & 302 \\
\hline & Interface & $\mathrm{NiGe}+\varepsilon^{\prime}-\mathrm{Ni}_{5} \mathrm{Ge}_{3}+$ white layer & 676 \\
\hline \multirow[t]{2}{*}{$\mathrm{AuGeSn} / \mathrm{Ni}$} & Substrate & $\mathrm{Ni}$ & 295 \\
\hline & Interface & $\mathrm{NiGe}+\varepsilon^{\prime}-\mathrm{Ni}_{5} \mathrm{Ge}_{3}$ & 617 \\
\hline
\end{tabular}


at.\%), are formed between the $\mathrm{Ni}$ substrate and liquid AuGeSn solder alloy (Fig. 10b). The growth of the $\varepsilon^{\prime}-\mathrm{Ni}_{5} \mathrm{Ge}_{3}$ phase is rather planar, whereas the interfacial NiGe phase is present as arrays of scallops along $\varepsilon^{\prime}-\mathrm{Ni}_{5} \mathrm{Ge}_{3}$ with thickness between $0.7 \mu \mathrm{m}$ and $3.5 \mu \mathrm{m}$. The thickness of the $\varepsilon^{\prime}-\mathrm{Ni}_{5} \mathrm{Ge}_{3}$ layer is around $1.5 \mu \mathrm{m}$. In the solder alloy, $(\mathrm{Ge})$ dendrites, AuSn (Au-45Sn, at.\%), and hexagonal close-packed (hcp) (Au,Sn) matrix (Au-13Sn, at.\%) were identified. Close to the edge, a thin white layer, similar to that detected in the $\mathrm{AuGeSb} / \mathrm{Ni}$ specimen, was observed (Fig. 10c). Compared with the AuGeSb/Ni system, the difference is that those "white particles" were always observed together with the formation of voids. These voids are believed to be Kirkendall voids, being induced through interdiffusion caused by the large difference in diffusivity between the two different species. ${ }^{26}$

In contrast to the wetting tests performed on the $\mathrm{Cu}$ substrate, where pronounced dissolution of $\mathrm{Cu}$ was observed, the presence of $\mathrm{Ni}$ was not detected in the bulk solder alloys of either specimen. Indeed, the formation of reactive intermetallic layers having compositions similar to the NiGe and $\varepsilon^{\prime}-\mathrm{Ni}_{5} \mathrm{Ge}_{3}$ compounds prevents dissolution of the $\mathrm{Ni}$ substrate into the liquid solder. This can be explained by the formation of a continuous layer of intermetallic compound(s) at the solid-liquid interface, and transportation of $\mathrm{Ni}$ must occur through this layer by solid diffusion, which is expected to substantially reduce the substrate dissolution rate.

\section{Microhardness}

The microhardness data of the bulk substrates $(\mathrm{Ni}$ and $\mathrm{Cu}$ ) as well as the solder-substrate interface for each specimen investigated are given in Table III. Note that the bulk solder alloys have a multiphase microstructure and the interfaces show a multilayer structure. Hence, the microhardness data are the average values in each area.

The interfaces of both AuGeSb and AuGeSn solder alloys in contact with $\mathrm{Cu}$ substrate exhibited similar microhardness values, and the same trend was also observed in the case of $\mathrm{Ni}$ substrate. Nevertheless, the microhardness of the interface in contact with $\mathrm{Ni}$ is much higher than that observed with $\mathrm{Cu}$, indicating the higher hardness of the Ni-Ge intermetallic compounds.

\section{CONCLUSIONS}

The wetting behavior of Au-Ge-X $(\mathrm{X}=\mathrm{Sb}, \mathrm{Sn})$ alloys on $\mathrm{Cu}$ and $\mathrm{Ni}$ substrates was studied by the sessile drop technique. The examined alloys exhibited excellent wetting on both types of substrate. Total spreading of both alloys on Cu substrate and of the AuGeSn alloy on Ni substrate was observed. The final contact angle of $\mathrm{AuGeSb} / \mathrm{Ni}$ was around $29^{\circ}$.

Compared with the Au-Ge eutectic alloy, addition of $\mathrm{Sb}$ and $\mathrm{Sn}$ decreases the alloy melting temperature, preserving the excellent wetting properties. Moreover, microstructure analysis of solder-substrate couples exhibits the formation of very thin interfacial layers, which is beneficial for joint performance since excessive growth of interface layer has a negative influence on electrical and mechanical properties. The obtained results indicate the promising prospect of using AuGeSb and AuGeSn ternary alloys as high-temperature lead-free solders.

\section{ACKNOWLEDGEMENTS}

This work was financially supported by the Swiss National Science Foundation (SNSF Project No. 200021_134575/1).

\section{REFERENCES}

1. V. Chidambaram, J. Hald, and J. Hattel, J. Alloy. Compd. 490, 170 (2010).

2. V. Chidambaram, J. Hattel, and J. Hald, Microelectron. Eng. 88, 981 (2011).

3. F.Q. Lang, H. Yamaguchi, H. Ohashi, and H. Sato, J. Electron. Mater. 40, 1563 (2011).

4. V. Chidambaram, H.B. Yeung, and G. Shan, J. Electron. Mater. 41, 2107 (2012).

5. B. Massalski, Binary Alloy Phase Diagrams (Metals Park, OH: ASM, 1990).

6. J.N. Lalena, N.F. Dean, and M.W. Weiser, Electron. Mater. 31, 1244 (2002)

7. S. Takeda, H. Fujii, Y. Kawakita, S. Tahara, S. Nakashima, S. Kohara, and M. Itou, J. Alloy. Compd. 452, 149 (2008).

8. J. Wang, C. Leinenbach, and M. Roth, J. Alloy. Compd. 485, 577 (2009)

9. J. Wang, C. Leinenbach, and M. Roth, J. Alloy. Compd. 481, 830 (2009).

10. Z. Wang and P. Wynblatt, Acta Mater. 46, 4853 (1998).

11. R.G. Gilliland, Weld. J. 43, 248 (1964).

12. C. Leinenbach, F. Valenza, D. Giuranno, H.R. Elsener, S. Jin, and R. Novakovic, J. Electron. Mater. 40, 1533 (2011).

13. C.Y. Li and X. Wang, Solder. Surf. Mt. Technol. 21, 4 (2009).

14. S.T. Cui, Z.F. Wang, H.B. Wu, and J.W. Liu, Rare Met. Mater. Eng. 37, 690 (2008).

15. L. Kaufman and H. Bernstein, Computer Calculation of Phase Diagrams (New York: Academic, 1970).

16. G. Zwingmann, Z. Metallkd. 55, 192 (1964).

17. D. Mouani, C. Souleau, and B. Legendre, J. Chim. Phys. 89, 2107 (1992).

18. N. Eustathopoulos, M.G. Nicholas, and B. Drevet, Wettability at High Temperatures, Vol. 3 (Oxford: Pergamon Materials Series, 1999).

19. F. Valenza, M.L. Muolo, and A. Passerone, J. Mater. Sci. 45, 2071 (2010).

20. M. Viviani, ICFAM-CNR Technical Report, CNR Genoa (1999).

21. L. Liggieri and A. Passerone, High Temp. Technol. 7, 82 (1989).

22. B. Sundman, B. Jansson, and J.O. Andersson, CALPHAD 9, $153(1985)$

23. S. Ogawa and D. Watanabe, J. Appl. Phys. 22, 1502 (1951).

24. B.W. Batterman, J. Appl. Phys. 28, 556 (1957).

25. R. Kubiak and J. Janczak, J. Alloy. Compd. 176, 133 (1991).

26. A. Paul, J. Mater. Sci.: Mater. Electron. 22, 833 (2011). 